\title{
DETERMINATION OF WATER VAPOUR ON BOGA STATION USING OBSERVABLE GPS
}

\author{
STEFANIA NIETO GUZMÁN., JULIÁN R. CAMARGO L., MIGUEL A. ÁVILA A. \\ Engineering Faculty, Universidad Distrital Francisco José de Caldas, Bogotá, Colombia
}

\begin{abstract}
This work shows the goodness that GPS technology offers the possibility of estimating the amount of precipitable water vapor in the atmosphere permanently and continuously because it does not have climatological limitations as well as its low cost, which contrasts with the conventional meteorological techniques such as the radio sounding, the radiometer and the photometers, which present limitations regarding temporality and spatiality in the data taking, likewise each country has a National Geodesic Network that if it is well densified, in this type of studies it offers a greater spatial resolution.
\end{abstract}

The distribution of water vapor in the atmosphere varies about latitude so that studies have determined that at higher altitudes, water vapor decreases, from this it is derived that in the poles the water vapor is 10 times smaller than in latitudes near the terrestrial equator, the water vapor also varies about the altitude, so that this decreases quickly as the altitude increases, thus concentrating in the layer of the atmosphere

KEYWORDS: Water Steam, Observable GPS, Meteorology, Tropospheric Delay, GNSS System

Received: Sep 24, 2020; Accepted: Oct 14, 2020; Published: Nov 18, 2020; Paper Id.: IJMPERDOCT202056

\section{INTRODUCTION}

In Colombia, a country with wide biodiversity in climates and species, it is of great importance to have methods of predicting meteorological phenomena to take advantage of the conditions that are presented in each of the different climatic phases. Even more so when a destabilizing phenomenon of the ecosystems occurs, such as global warming, it becomes really important to obtain or make approaches to methods that allow monitoring the amount of water in the atmosphere, which is concentrated in a gaseous form in the troposphere, becoming a key element for the prediction of rainy or dry seasons depending on the concentration in the environment. The water vapor present in the atmosphere is obtained from conventional techniques such as radiosondes, however, these techniques have some limitations linked to the variability of time and their high cost.

The GPS (Global Positioning System) is a satellite navigation system widely adopted for the instantaneous position and speed of a point anywhere on the surface of the earth in any weather condition [1], a feature that makes this system an ally in the recovery of water vapor present in the atmosphere, because this thanks to its physical foundation allows the precise quantification of water vapor present in the atmosphere derived from an adequate post-processing of the GPS observables and accompanied by meteorological measurements such as humidity, temperature and pressure on the earth's surface, generating the possibility of constant monitoring of this atmospheric variable, so that Bevis et al. [2] propose GPS networks as a remote sensing system that allows the study of water vapor present in the atmosphere with a good precision derived from the study of the GPS signal, 
becoming a tool that allows monitoring this time variable according to its spatial distribution and with a time resolution of 10 minutes; since then, different studies have been developed with the purpose of determining the effectiveness and reliability of the system in the study of this atmospheric component.

The attempt to use satellite technology to monitor atmospheric water vapor has been such that, for example, Valdés, Cano, Sánchez \& Gonzalo [3], are working on the E-VAGP - GNSS (Water Vapour Programme) project, in which they calculate the tropospheric delay and water vapor in as many stations as possible in the European area, in order to carry out continuous-time monitoring of this variable, so that if the results obtained are reliable, these data can be starting data for numerical weather prediction models.

In the case of Latin America, Cioce et al. [4] carried out the calculation of water vapor over the MARA station in Maracaibo city, Venezuela, and pointed out that several trials have been developed worldwide that have shown that the recovery of this atmospheric variable using GPS observations is reliable, effective and accurate when compared with traditional meteorological techniques, on the other hand, in Argentina Fernandez et al. [5] are focused on obtaining values of precipitable water vapor as a by-product derived from rigorous processing of GPS data; at a national level, [6] in their work is dedicated to present the application of GPS, making a statistical treatment to data of precipitable water vapor in the atmosphere (PWV) from the Souminet International Network.

In this sense it has been chosen to determine the viability and reliability of an estimation of the water vapor contained on the BOGA station located in the city of Bogota (Colombia) attached to the MAGNA-ECO NETWORK making use of Neill's mapping function for the treatment of the tropospheric delay on the signal, considering that for this case there are no in situ meteorological data, where the processing is done using the GAMIT/GLOBK software, the results derived from the processing are later compared with atmospheric water vapor data from radio sounding measurements.

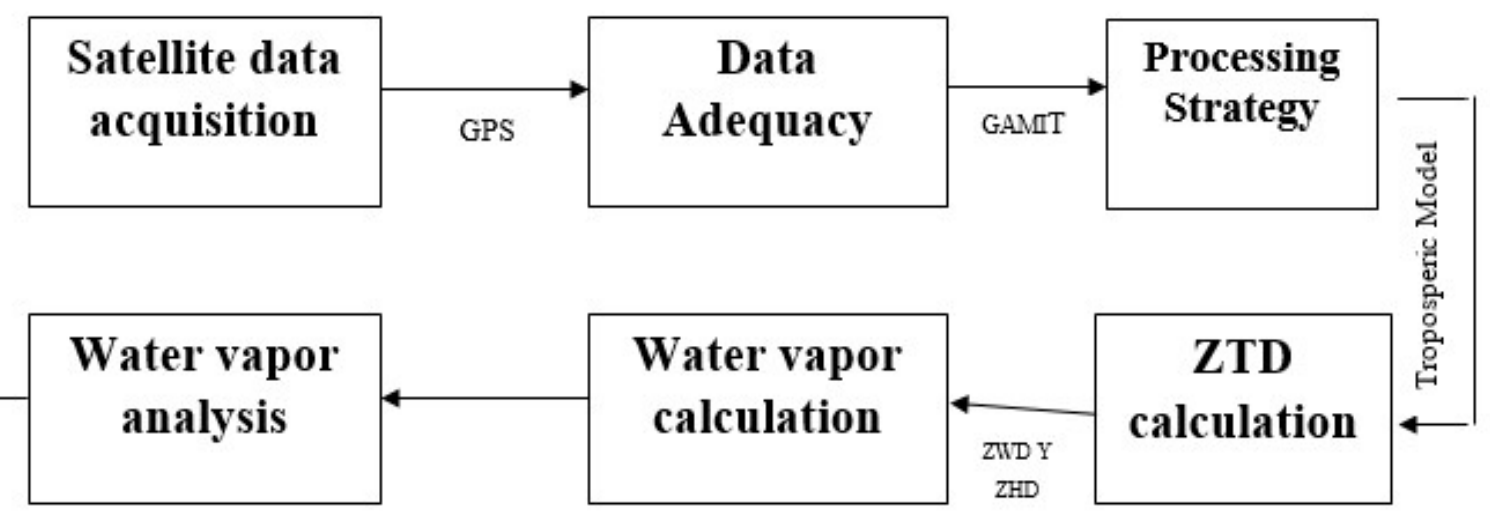

\section{Conclusions}

Figure 1: Methodological Table-Self-made

\section{MATERIALS AND METHODS}

The methodology that was developed to determine the atmospheric water vapor over the BOGA station, can be seen in 
Figure 1 so that the project was worked in eight stages, ranging from the acquisition of satellite data to the conclusions derived from the results obtained.

\subsection{Data Acquisition and Adaptation}

We worked with GPS data from BOGA and TUNA stations, which are associated with RED-MAGNAECO and in turn, are linked to MAGNA SIRGAS. The GPS data processed corresponds to GPS days 153 to 182 and 306 to 335 for 2012 and GPS days 152 to 182 and 305 to 334 for 2013 and 2014, which in the global calendar refer to the months of June and November each year.

The processing seasons were selected considering that for the year 2013 according to the records of the meteorological station UNIV NACIONAL attached to IDEAM - Institute of Hydrology, Meteorology and Environmental Studies of Colombia in the month of June was obtained 10 days with presence of rainfall, and for the month of November 21 days was presented record of rainfall, so that they are associated with a dry season (June) and a time with presence of rainfall (November), according to this works the same times for the years 2012 and 2014.

The GPS data was supplied by IGAC - Geographic Institute Agustín Codazzi through FTP 190.24.137.74 and the download of which is associated with a user and password assigned by the same entity. In the case of brdc or broadcast files (transmitted ephemeris) which contain useful information to determine the position of the satellite for and the files. sp3 (final ephemeris) which contains the precise orbital and clock information, is downloaded from CDDIS - NASA's Archive of Space Geodesy Data.

Once the data are obtained, they are adapted according to the requirements of the GAMIT/GLOBK software [7], in such a way that in the case of GPS data obtained in the observation index format (. o), they are renamed in lower case, to proceed with the processing.

\section{ZTD PROCESSING AND CALCULATION STRATEGY}

Depending on the propagation of electromagnetic signals, such as the GPS signal, two atmospheric layers are considered: the ionosphere and the troposphere. In this case, special attention is focused on the latter, since it contains practically all water vapor and aerosols.

The troposphere is characterized by being the most superficial layer and presents an average thickness of $12 \mathrm{~km}$, it has a high concentration of gaseous substances such as nitrogen, oxygen, carbon dioxide, water vapor, among other gases; it contains approximately $70 \%$ of the total mass of the atmosphere and most of the meteorological phenomena occur there [8].

The GPS signal in its journey from the satellite to the receiver, is negatively influenced in its passage through the ionosphere and the troposphere, producing there a source of error in positioning called ionospheric delay and tropospheric delay, generating an uncertainty in the calculation of coordinates, the influence of the troposphere on the signal is greater, as this is a medium in which it interacts with particles such as water vapor, for this reason the delay is a little complex to determine as a function of the path that follows the signal.

To recover water vapor over a GPS station, it is necessary to determine the delay that suffers the signal in the troposphere, this delay is divided into a hydrostatic component and a wet component, the hydrostatic component, constitutes $90 \%$ of the total tropospheric delay and can be determined from surface pressure measurements, for this reason, 
this component is easily modeled to be stable, the wet component is dependent on water vapor present during the path of the signal, being variable in time. To reduce the tropospheric delay that suffers the signal, models such as Saastamoinen and Holfield are used that depend on atmospheric variables, which in turn can be obtained from atmospheric models such as the GPT - Global Pressure and Temperature, these tropospheric models also require mapping functions such as Neill or Herring.

Now, the tropospheric refractivity is given by (1), where is the refractivity:

$$
\Delta^{\text {Trop }}=10^{-6} \int N^{\text {Trop }} \mathrm{ds}(1)
$$

Equation (2) corresponds to the tropospheric refractivity exposed by Kleusberg \& Taunissen [9], which is a function of the temperature $(\boldsymbol{T})$ in degrees Kelvin, with the partial pressure of dry gases $\left(\boldsymbol{P}_{d}\right)$ in millibars and with the partial pressure of water vapor in millibars, which in turn is worked with the coefficients, $\boldsymbol{K}_{1}, \boldsymbol{K}_{2}, \boldsymbol{K}_{\mathbf{3}}$ and determined empirically and the factors of compressibility of dry air and water vapor $\boldsymbol{z}_{d}^{-1}$ y $\bar{z}_{w}^{-1}$

$$
N=k_{1}\left(\frac{P_{d}}{T}\right) z_{d}^{-1}+\left[k_{2}\left(\frac{e}{T}\right)+k_{3}\left(\frac{e}{T}\right)\right] z_{w}^{-1}(2)
$$

The refractivity exposed in (2) is composed of two terms, where the first refers to the dry component and the second to the wet component, so that the total tropospheric refractivity is exposed in (3), where $N_{d}^{T r o p}$ and $N_{w}^{T r o p}$ are the dry and wet components.

$$
\Delta^{T r o p}=10^{-6} \int N_{d}^{T r o p} d s+10^{-6} \int N_{w}^{T r o p} d s(3)
$$

In GPS processing, the tropospheric effect is treated according to (4), where $Z H D$ and $Z W D$ are the zenithal delay of the dry and wet components, respectively, $\boldsymbol{m} \boldsymbol{f}_{H}$ and $\boldsymbol{m} \boldsymbol{f}_{w}$ are the mapping functions for the dry and wet components, and the other parameters are gradients according to the azimuth of the line from the satellite to the receiver considered $\theta_{\text {REC }}^{S V}$

$$
\begin{aligned}
& \Delta T_{R E C}^{S V}(t, \theta, Z)=m f_{H}\left(Z_{R E C}^{S V}\right) \times Z H D_{R E C}+m f_{W}\left(Z_{R E C}^{S V}\right) x Z W D_{R E C}+\Delta^{n} \Delta T_{R E C}(t) \frac{\partial f}{\partial z} \cos \theta_{R E C}^{S V}+ \\
& \Delta^{\theta} \Delta T_{R E C}(t) \frac{\partial f}{\partial z} \sin \theta_{R E C}^{S V}
\end{aligned}
$$

For the treatment of the tropospheric delay in the signal, the delay of each one of the components in the zenith is considered, is this the shortest distance between the satellite and the receiver.

Figure 2 corresponds to the processing strategy for the recovery of water vapor on the BOGA station using the software GAMIT/GLOBK in its version 10.5, for the case is required to configure a series of files in which the processing strategy is configured, for the case focuses special attention on the configuration of the file sestbl; file in which the conditions for the treatment of tropospheric delay on the signal are configured. 


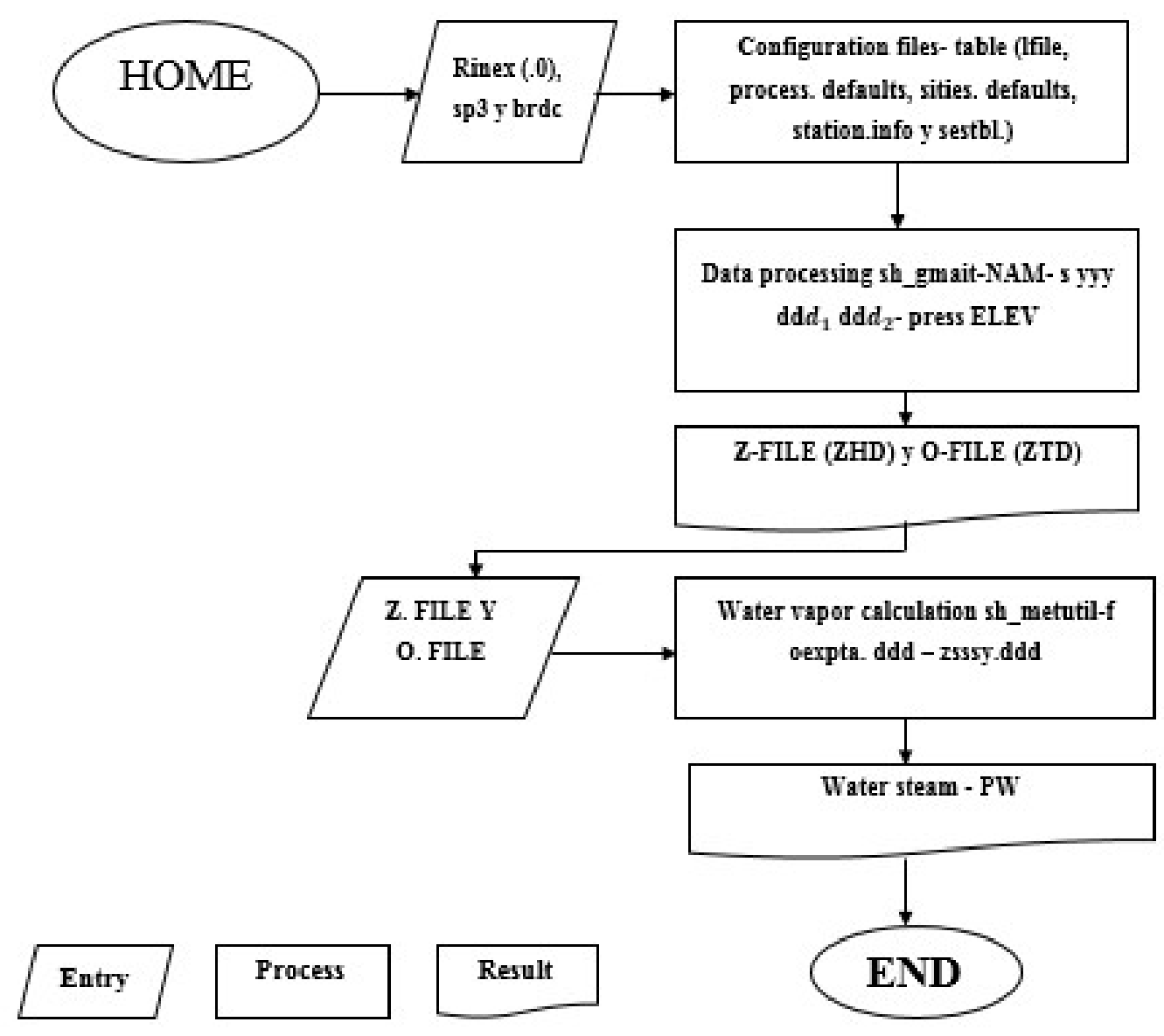

Figure 2: Processing Strategy-Self-made

For the processing of the GPS data, processing using the tropospheric model was carried out, the one of Saastamoinen based on the assumption that the tropospheric refractivity can be deduced from the gas law, here the signal delay is expressed in meters as a function of the zenithal angle of the satellite, the temperature ( ${ }^{\circ}$ Kelvin), the atmospheric pressure (millibars) and the water vapor pressure (millibars); In this case, it was decided to use Neil's mapping functions known as NMF (Niell Mapping Function), under the premise that there is no meteorological data in situ. These functions were chosen because the coefficients required are independent of the meteorological measurements and this has been designed as a solution to the correction of the delay in the neutral atmosphere in those places where there is no meteorological information; the coefficients determined are a function of latitude and day of observation as seen in (5).

$$
\mathrm{a}=\mathrm{a}(\varphi)_{\text {Averange }}-\mathrm{a}(\varphi)_{\text {Amplitude }} x \cos \left[2 \pi \frac{D o Y-D o Y_{0}}{365.25[d]}\right] \text { (5) }
$$

It is important to consider that these mapping functions, work as a low-pass filter that allows the passage of the low frequencies translated for the case in the delay that suffers the signal.

Once the troposphere has been modeled and the total tropospheric delay (ZTD) and the dry tropospheric delay $(\boldsymbol{Z H D})$ are obtained; the wet tropospheric delay $(\boldsymbol{Z W D})$ is deduced and later a conversion is made depending on thermodynamic and physical constants as well as on the average temperature of the variable troposphere that presents greater influence in the recovery of atmospheric water vapour over the station; in (6) the mathematical expression that 
allows the conversion to precipitable water vapour derived from the use of GPS observables is observed.

$$
P W=Z W D * Q(6)
$$

Where: is the precipitable water vapor expressed in millimeters and corresponding to the height of the water column $\boldsymbol{Z W D}$, is the tropospheric retardation and $Q$ is the conversion factor, which is given by the expression (7), where $\boldsymbol{R}_{w}$ is the constant of specific gases corresponding to water vapor, $\boldsymbol{\rho}$ is the density of water, $\boldsymbol{k}_{\mathbf{2}}$ and $\boldsymbol{k}_{\mathbf{3}}$ are the constants of refractivity, $\boldsymbol{M}_{\boldsymbol{w}}$ is the molar mass of water vapor and $\boldsymbol{T}_{\boldsymbol{m}}$ is the mean temperature of the troposphere.

$$
Q=10^{-6} * R_{W^{*}} * \rho *\left(k_{2}+\frac{k_{3}}{T_{m}}\right)=10^{-6} * \frac{R_{W}}{M_{W}} * \rho *\left(k_{2}+\frac{k_{3}}{T_{m}}\right)(7)
$$

\section{CONCLUSIONS}

The analysis that has been carried out from the results obtained after the processing, consists of: the evaluation of the results obtained from the comparison of the same with the data of radio soundings, procedure that has been carried out only for the station BOGA, the behavior of the water vapor is analyzed based on the temperature and the registries of precipitations for the months of June and November of year 2013 and finally an analysis of the daily behavior of the water vapor is carried out considering a day with precipitations and one without registry of precipitations.

Once the GPS data has been processed with the GAMIT/GLOBK software and using the sh_methyl module, the water vapor calculated every two hours is obtained for the BOGA and TUNA stations in such a way that 13 water vapor values are obtained for each day and for each of the stations; in this case, a total of 180 days have been processed, considering that each month has 30 days.

Comparing GPS and Radiosonde Data and in order to evaluate the water vapor (PW) values obtained from the processing of GPS data is a comparison of these with data from radio soundings, this comparison has been made only with results obtained for the BOGA station, since these can be compared with the radio sounding data obtained from the El Dorado Airport Station, where radio soundings are made at 12 o'clock every day.

For an adequate analysis we have taken the water vapor values obtained at 12 hours after processing for the months of November 2012, June and November 2013 and June 2014, in order to have time series of the same nature, we observe the information regarding the El Dorado Airport Station.

\begin{tabular}{|l|l|l|l|l|}
\hline \multicolumn{1}{|c|}{ Station } & \multicolumn{1}{|c|}{ Latitude [N] } & \multicolumn{1}{|c|}{ Longitude [W] } & Height [m] & \multirow{2}{*}{ Distance } \\
\cline { 1 - 4 } BOGA & $04^{\circ} 38^{\prime} 19.25^{\prime \prime}$ & $74^{\circ} 04^{\prime} 47.82^{\prime \prime}$ & 2610.37 & \multirow{2}{*}{$9.5 \mathrm{Km}$} \\
\hline Airport Eldorado & $04^{\circ} 41^{\prime} 49.67^{\prime \prime}$ & $74^{\circ} 08^{\prime} 36.96^{\prime \prime}$ & 2546.0 & \multirow{2}{|c|}{} \\
\hline
\end{tabular}

The atmospheric water vapour values for $12 \mathrm{~h}$ for measurements obtained from GPS data (PW), and the water vapour values obtained from radiosonde measurement (PWRS). 


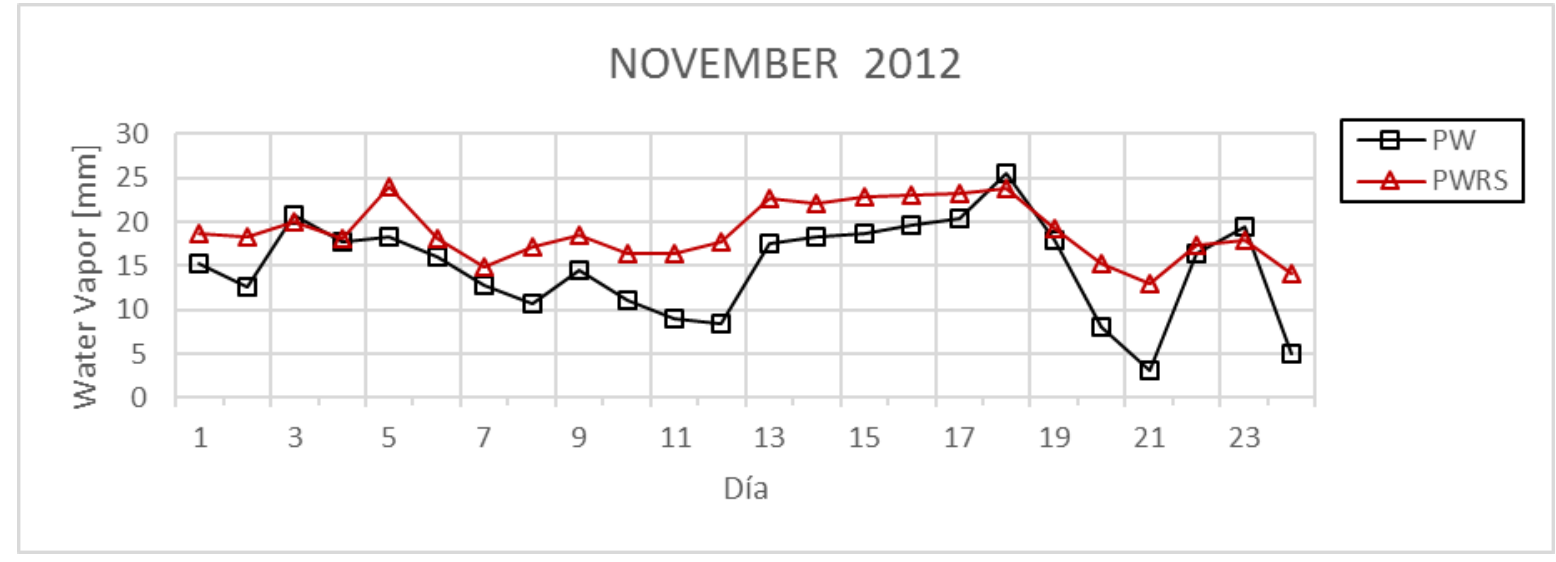

Figure 3: Water vapor values of PW (GPS) and PWRS (Radiosonde) for the month of November 2012.

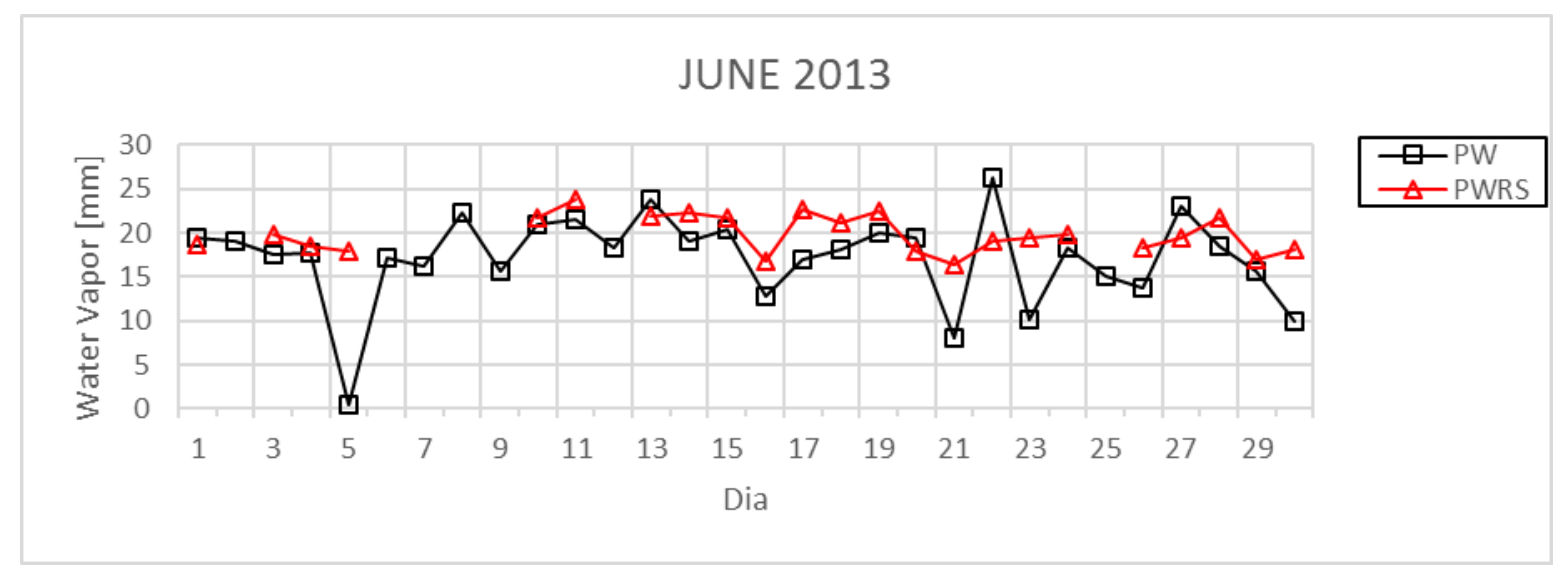

Figure 4: Water vapor values of PW (GPS) and PWRS (Radiosonde) for the month of June 2013.

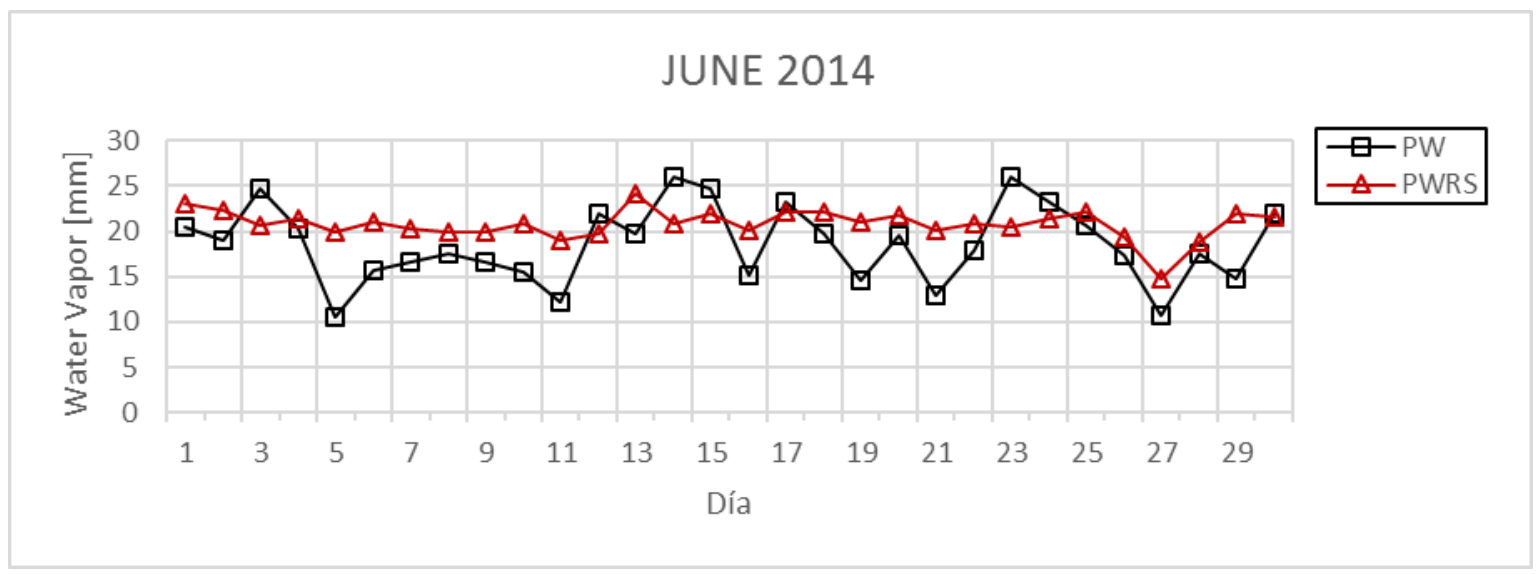

Figure 5: Water vapor values of PW (GPS) and PWRS (Radiosonde) for the month of June 2014 


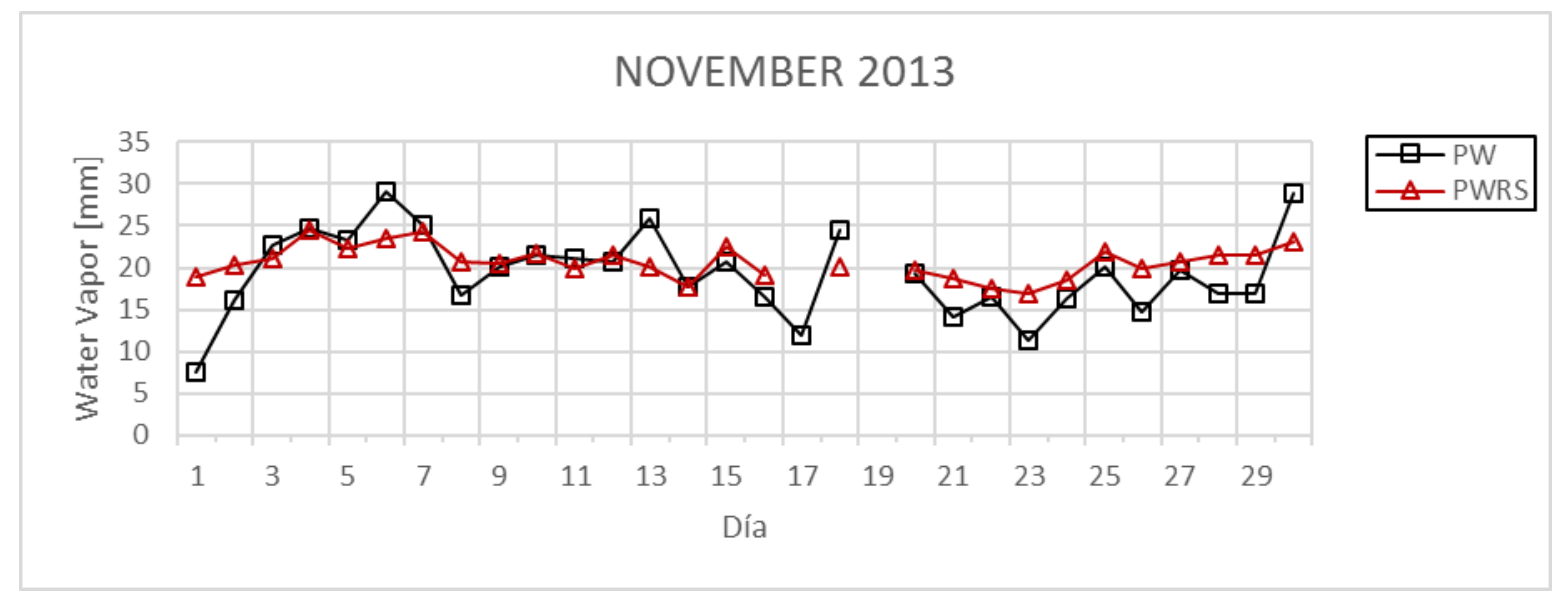

Figure 5: Water vapor values of PW (GPS) and PWRS (Radiosonde) for the month of November 2013.

According to the results obtained, by November 2012 the maximum and minimum value of water vapor obtained by GPS observables is $25.53 \mathrm{~mm}$ and $3.14 \mathrm{~mm}$ respectively, while the values for radiosonde are $23.9 \mathrm{~mm}$ for the maximum and $18.85 \mathrm{~mm}$ for the minimum.

For the month of June 2013 has that the maximum water vapor obtained by GPS is $26.3 \mathrm{~mm}$ while for the PWRS is $23.78 \mathrm{~mm}$ and the minimum is $0.41 \mathrm{~mm}$ for GPS and $16.36 \mathrm{~mm}$ for PWRS, however the average value obtained for this year in June is $17.17 \mathrm{~mm}$ for PW by GPS and $19.83 \mathrm{~mm}$ for PWRS, which has that the average value in this month to compare them are not far away.

For the month of November 2013 is obtained that the average value for the month is $19.34 \mathrm{~mm}$ and $20.64 \mathrm{~mm}$ for water vapor values obtained from observable GPS and radio sounding measurements respectively at 12 pm, however it should be noted that for the first day of November this year was obtained a value of $7.62 \mathrm{~mm}$, which was the minimum, by GPS while for that day at $12 \mathrm{pm}$ the water vapor recorded by the station Avenida El Dorado was $18.88 \mathrm{~mm}$.

According to the results obtained, it is obtained that the water vapor values obtained by GPS present a positive correlation with the values recorded by the Avenida El Dorado station, and that they present a dispersion with respect to the average close to $4 \mathrm{~mm}(3.96 \mathrm{~mm})$.

When comparing the water vapor data from BOGA station with the data from the Avenida Eldorado station, it is evident that a correlation greater than 0.50 is obtained, however the adjustment of these is not very high, being below $90 \%$; the low adjustment of these due to the differences between the water vapor obtained with GPS observables and the water vapor measured by radio sounding can be influenced by the lack of meteorological information in situ (temperature, relative humidity and pressure) for the calculation of water vapor with GPS technology.

The baseline worked (BOGT-BOGA) could influence the calculation of water vapor for the month of June 2012 in the BOGA station, showing for this year values of atmospheric water vapor close to $10.00 \mathrm{~mm}$, when it has that for the years 2013 and 2014 the average water vapor content on this station is between $17.78 \mathrm{~mm}$ and $20.44 \mathrm{~mm}$.

When evaluating the behavior of water vapor as a function of rainfall and temperature, it is found that the average content of water vapor is higher on those days when there is a record of rainfall, while the higher the temperature the lower the content of water vapor in the atmosphere, behavior that was observed for the months of June and November 2013. 
The module sh_metutil of the GAMIT/GLOBK software allows to obtain reliable results on the calculation of water vapour present in the atmosphere even when no meteorological information is obtained on site.

\section{ACKNOWLEDGMENTS}

The authors would like to thank the Universidad Distrital Francisco José de Caldas and the GITEM research group that supported the development and testing of the project.

\section{REFERENCES}

1. KureKar, R. G., \& Kuraishi, M. A. (2012). Determination of Precipitable Water Vapour Using Global Positioning System. International Journal of Geology, Earth and Environmental Sciences, 2, 51-57

2. Bevis, M., Businger, S., Herring, T. A., Rocken, C., Anthes, R. A., \& Ware, R. H. (1992). GPS meteorology: Remote sensing of atmospheric water vapor using the global positioning system. Journal of Geophysical Research: Atmospheres, 97(D14), 15787-15801. doi: 10.1029/92JD01517.

3. Valdés, M., Cano, M. A., Sánchez, J. A., \& Gonzalo, P. (2012). Determination of the tropospheric delay with GNSS in almost real time by the NGI in the European E-GVAP project. Presented at the 7th HISPANIC-PORTUGUESE ASSEMBLY OF GEODESY AND GEOPHYSICS, DONOSTIA, SAN SEBATIAN. Recovered from: http://www.ideandalucia.es/portal/delegate/content/419f7f3b-b2ab-4f67-9c11-19247b8f75dd

4. Cioce, V., Hoyer, M., Wildermann, E., Royero, G., \& Díaz, A. (2011). Determination of tropospheric water vapor through GPS observations: first trials in Venezuela. Interciencia, 36(10), 721-730.

5. Fernández, L. I., Meza, A. M., \& Natali, M. P. (2009). Determination of precipitable water vapor (PWV) content from GPS measurements: first results in Argentina. Geoacta, 34(2), 35-57.

6. Šverko Navarrete, M. (2012). Method for estimating precipitable water vapor, by remote detection, using the global positioning system (GPS) with application in the improvement of the weather forecast in the city of Bogotá, D.C. (masters). National University of Colombia. Recovered from: http://www.bdigital.unal.edu.co/9918/

7. Herring T. A., King R. W., McClusky S. C. GAMIT Reference Manual GPS Analysis at MIT, Department of Earth, Atmospheric, and Planetary Sciences Massachusetts Institute of Technology.

8. Sapucci, L. (2001). Estimation of atmospheric water vapor and evaluation of tropospheric zenithal delay modeling using GPS. 2001. 167 f. Dissertation (Master in Cartographic Sciences)-College of Sciences and Technology, Universidade Estadual Paulista, Presidente Prudente. Recovered from http://base.repositorio.unesp.br/bitstream/handle/11449/88549/sapucci_lf_me_prud.pdf?sequence=1\&isAllowed=y

9. Kleusberg, A., \& Teunissen, P. (1998). GPS for geodesy. Berlin: Springer.

10. Niell, A. (1996). Global mapping functions for the atmosphere delay at radio wavelengths. J. Geophys. Res., 101 (B2), 3227. Recovered from: http://dx.doi.org/10.1029/95jb03048

11. Jade, S., \& Vijayan, M. S. M. (2008). GPS-based atmospheric precipitable water vapor estimation using meteorological parameters interpolated from NCEP global reanalysis data. Journal of Geophysical Research: Atmospheres (1984-2012), 113(D3). Recuperado a partir de http://onlinelibrary.wiley.com/doi/10.1029/2007JD008758/full

12. Troller, M., Geiger, A., Brockmann, E., Bettems, J.-M., Bürki, B., \& Kahle, H.-G. (2006). Tomographic determination of the spatial distribution of water vapor using GPS observations. Advances in Space Research, 37(12), 2211-2217. doi:10.1016/j.asr.2005.07.002 
13. Seco, A., Ramírez, F., Serna, E., Prieto, E., García, R., Moreno, A., Cantera, J., Miqueleiz, L. and Priego, J. (2012). Rain pattern analysis and forecast model based on GPS estimated atmospheric water vapor content. Atmospheric Environment, 49 , pp.85-93.

14. Choy, S., Wang, C., Yeh, T., Dawson, J., Jia, M., \& Kuleshov, Y. (2015). Precipitable Water Vapor Estimates in the Australian Region from Ground-Based GPS Observations. Advances In Meteorology, 2015, 1-14. http://dx.doi.org/10.1155/2015/956481

15. Šverko Navarrete, M. (2012). Método de estimación del vapor de agua precipitable, por detección remoto, mediante el sistema de posicionamiento global (GPS) con aplicación en el mejoramiento del pronóstico del estado del tiempo en la ciudad de Bogotá, D.C. (masters). Universidad Nacional de Colombia. Recuperado a partir de http://www.bdigital.unal.edu.co/9918/ 